\title{
Geographical Clustering of Pancreatic Cancers in the Northeast Nile Delta Region of Egypt
}

\author{
A. S. Soliman, ${ }^{1}$ X. Wang, ${ }^{2}$ J.-D. Stanley, ${ }^{3}$ N. El-Ghawalby, ${ }^{4}$ M. L. Bondy,${ }^{5}$ F. Ezzat, ${ }^{4}$ A. Soultan, ${ }^{4}$ M. Abdel-Wahab, ${ }^{4}$ \\ O. Fathy, ${ }^{4}$ G. Ebidi, ${ }^{4}$ N. Abdel-Karim, ${ }^{5}$ K.-Anh. Do,${ }^{2}$ B. Levin, ${ }^{6}$ S. R. Hamilton, ${ }^{7}$ J. L. Abbruzzese ${ }^{8}$ \\ ${ }^{1}$ Department of Epidemiology, University of Michigan School of Public Health, Ann Arbor, Michigan, USA \\ 2 Department of Biostatistics, The University of Texas M. D. Anderson Cancer Center, Houston, Texas, USA \\ ${ }^{3}$ Deltas-Global Change and Coastal Geoarchaeology Programs, U.S. National Museum of Natural History, Smithsonian Institution, Washington, \\ D.C., USA \\ ${ }^{4}$ Gastrointestinal Surgical Center, Mansoura University, Mansoura, Egypt \\ ${ }^{5}$ Department of Epidemiology, The University of Texas M. D. Anderson Cancer Center, Houston, Texas, USA \\ ${ }^{6}$ Division of Cancer Prevention, The University of Texas M. D. Anderson Cancer Center, Houston, Texas, USA \\ ${ }^{7}$ Division of Pathology and Laboratory Medicine, The University of Texas M. D. Anderson Cancer Center, Houston, Texas, USA \\ ${ }^{8}$ Department of Gastrointestinal Medical Oncology, The University of Texas M. D. Anderson Cancer Center, Houston, Texas, USA
}

Received: 16 June 2005/Accepted: 26 September 2005

\begin{abstract}
The northeast Nile Delta, Egypt's most polluted region, appears to have a high incidence of pancreatic cancer. We sought to determine whether there is any geographic clustering of pancreatic cancers there and, if so, whether such clustering might be associated with environmental pollution. Using data from the medical records of the Gastrointestinal Surgical Center of Mansoura University in the Dakahleia Province of Egypt and detailed geographical maps of the northeast Nile Delta region, we plotted the residences of all 373 patients who had pancreatic cancer diagnosed between 1995 and 2000. The study region has 15 administrative districts, whose centroid coordinates, population, and number of pancreatic cancer patients were determined for this study. Monte Carlo simulation identified statistically significant clustering of pancreatic cancer in five subdivisions located near the Nile River and Delta plains. This clustering was independent of population size and formed two larger clusters. When data were analyzed by sex, clustering of pancreatic cancer was observed in the same five subdivisions for men but only two subdivisions showed clustering for women. Together, our data suggest that there is clustering of pancreatic cancer cases in the northeast Nile delta region and that this clustering may be related to water pollution. Our data also warrant future studies of the association between water pollution and pancreatic cancer in the region.
\end{abstract}

Pancreatic cancer is a lethal disease that quickly deprives patients of quality of life. It is the fifth leading cause of cancerrelated death in the United States. However, little is known

Correspondence to: Amr. S. Soliman; email: asoliman@umich.edu about its etiology. Smoking is the only known lifestyle risk factor for pancreatic cancer (Fryzek et al. 1997; Potter 2002). Although some studies failed to identify any occupational risk factors (Mack et al. 1985; Falk et al. 1990), others have established a list of putative occupational factors that includes exposure to pesticides (Alavanja et al. 1990; Forastiere et al. 1993; Partanen et al. 1994; Fryzek et al. 1997; Cantor and Silberman 1999; Porta et al.1999; Slebos et al. 2000; Ji et al. 2001), exposure to manufacturing paints and pigments (Sheffet et al. 1982; Norell et al. 1986; Raymond and Bouchardy 1990), metalworking (Maruchi et al. 1979; Sparks and Wegman 1980; Mallin et al. 1986; Silverstein et al. 1988; Rotimi et al. 1993; Park and Mirer 1996), and soldering (Ji et al. 1999). The carcinogens responsible for pancreatic cancer have yet to be determined.

Although pancreatic cancer is rare in developing countries, including most of Egypt, the northeast Nile delta region (Dakahleia Province) exhibits a large number of pancreatic cancers (Soliman et al. 2002). This region is the most polluted in Egypt (Issa 1994; Badawy et al. 1995; Dewidar and Khedr 2001; Abdel-Sabour and Abdel-Basset 2002; Zohny 2002). Most of Egypt's 68 million residents live in or around the Nile Valley and Nile delta, which constitute only $4 \%$ of the country's land. The industrialization and urbanization of these areas has occurred rapidly, without protective legislation, has led to dangerous increases in environmental carcinogens (Gusten et al. 1994). Industrial waste and by-products, agricultural wastewater, and nonrecyclable waste are being increasingly dumped into the Nile, with the result that the river, especially in its lower stretch, is now heavily polluted with heavy metals, pesticides, and hydrocarbons (Badawy et al. 1995). More draining of water amount occurs in the northeast delta region than other parts of the delta. Moreover, sewage from Cairo and 5 provinces in the delta eventually reaches by open sewage drains into the Manzala Lagoon in the northeast Nile delta. 
Residents of Mansoura, the capital of Dakahleia Province, show signs of heavy metal exposure (Mortada et al. 2002). Thus, the northeast Nile delta region offers a unique setting for studying the potential geographic clustering and environmental etiology of pancreatic cancer.

Mapping the incidence of disease is an established and important means of analyzing regional public health and identifying disease clusters (Lawson 2001). Such mapping may utilize routinely collected public health data or data collected in small-scale ecological studies of particular diseases (Walter 1993). Unfortunately, in many developing countries, including Egypt, national cancer incidence data are unavailable. Thus, the data from small-scale studies are of particular importance in public health surveillance, especially for assessing disease clustering in order to identify, prevent, and control potential environmental hazards (Walter 1993).

Using a similar approach, our study goal was to determine whether there are any geographic clustering of pancreatic cancers in Egypt's northeast Nile delta region (Dakahleia Province) and, if so, whether such clustering might be associated with environmental pollution.

\section{Methods}

\section{Study Subjects and Locales}

We reviewed the medical records of the Gastrointestinal Surgical Center (GSC) of Mansoura University for the period from 1995 to 2000 to determine all patients diagnosed with pancreatic cancer. Of 728 pancreatic cancer patients diagnosed there during this period, we identified 367 patients whose residence was reported and confirmed to be in Dakahleia Province in the northeast Nile delta region. It is important to note that this region has a stable population that is not subject to much inter- or intraprovince migration (CAPMAS 2001). In addition, we reviewed the records of three cancer centers in the Nile delta region and Cairo that possibly had received patients from Dakahleia Province and identified six additional patients. Thus, our final study population was 373 patients who represented the denominator used in this study. We have previously described the GSC and the clinical characteristics of our study population (Soliman et al. 2002). Briefly, the GSC of Mansoura University was established in 1976 as a Gastroenterology surgical unit within the Department of Surgery of the Faculty of Medicine, Mansoura University. Since 1992, the center has been a separate entity serving as a referral gastrointestinal surgery center. In addition, this center performs a full range of diagnostic gastroenterologic techniques. Forty percent of patients are treated free-of-charge, $40 \%$ are covered by national health insurance plans, and $20 \%$ paid privately. More than $90 \%$ of patients seen at GSC reside in the Central and East Nile delta regions. The predominantly rural province of Dalakhleia has the largest population of all provinces in the Nile delta region (Soliman et al. 2002). The total population of Dakahleia province is 2,758,251 individuals, and the area of the province is $3470.9 \mathrm{~km}^{2}$ (CAPMAS 2001).

\section{Mapping}

Detailed maps of Egypt and the Nile delta region and the 15 districts of the Dakahleia Province were obtained from the National General Survey Authority in Cairo, Egypt, and National Imagery and Mapping Agency (NIMA) through the U.S. Geological Survey, Reston, Virginia, USA. Each map was drawn to a scale of 1:50:000 and depicted details of the region including cities, towns, villages, streets, fresh water sources, irrigation channels and drainage canals, and agricultural fields and the crops grown in them. The paper maps of NIMA included street and village names and locations, and coordinate longitudes and latitudes were assigned accordingly.

As we reviewed the medical records of the patients from GSC mentioned above, we abstracted the following information on all patients: age, sex, and address (village in rural areas and street in town and cities). We then located the addresses of all patients on the district maps, identified the longitude and latitude of each case residence, and plotted the residence of cases on the maps (Figure 1B-E). We used paper maps of the NIMA that included street and village names and location and coordinate longitudes and latitudes were assigned accordingly.

\section{Statistical Analysis}

We implemented the cluster finding method developed by Kulldorff and Nagarwalla (1995). The method is based on the likelihood ratio test. We partitioned our study region of Dakahleia Province into administrative subdivisions/districts, called "cells." For each cell, we recorded the population size and the number of cases.

Let $N$ be the total population and $C$ be the total number of cases in the study region. Throughout the analysis, we conditioned on the total number of cases in the dataset and hence, we treated $C$ as a constant. The null hypothesis was $\mathrm{H}_{0}: p=q$ and the alternative hypothesis was $\mathrm{H}_{1}: p>q$, where $z$ denotes the cell in our study region, $p$ denotes the probability of being a patient within the cell, and $q$ denotes the probability of being a case outside the zone.

For a large dataset, it is impossible to find the exact distribution of $\lambda$ by enumerating each of all possible outcomes. Therefore, we used Monte Carlo method to sample from exact distribution of $\lambda$. In our analysis, Monte Carlo simulation consisted of 999 replicates, each of which involved choosing $C$ individuals at random from the total $N$ individuals and labeling them as cases. For each replicate, we calculated the value of the test statistic $\lambda$. We ordered the collection of 1000 values of $\lambda$ coming from the 999 replicates and from the data itself, with the highest value assigned rank 1 . This means that we could obtain a significant result at the $5 \%$ level if the $\lambda$ from the real data was among the highest 50 of these $1000 \lambda$ 's. In summary, Monte Carlo method generated an empirical distribution of pancreatic cancer cases under the null hypothesis assuming no clustering. $\lambda$ is the statistical value that measures the modality of clustering. Large values for $\lambda$ mean high clustering effect.

\section{Results}

Our statistical analysis showed significant differences in the distribution of cases across districts independent of population size (Table 1). Five districts (districts 1, 3, 8, 13, and 15) showed significantly greater clustering of patients than did the other 10 districts (Table 1 and Figure 1B,C). When we studied the distribution of patients in these five districts by sex, we found clustering of men with pancreatic cancer in the same five districts (Table 2), but clustering of women with pancreatic cancer in only two of them (i.e., districts 1 and 15) (Table 3).

Because pancreatic cancer is related to age, it was critical for this study to look at age distribution in all study districts. It was essential to know whether real clusters exist or districts of clusters were only areas with older people. We retrieved age distribution of the 15 districts and examined the proportion of older subjects (50 years or older) in relation to the total pop- 
A
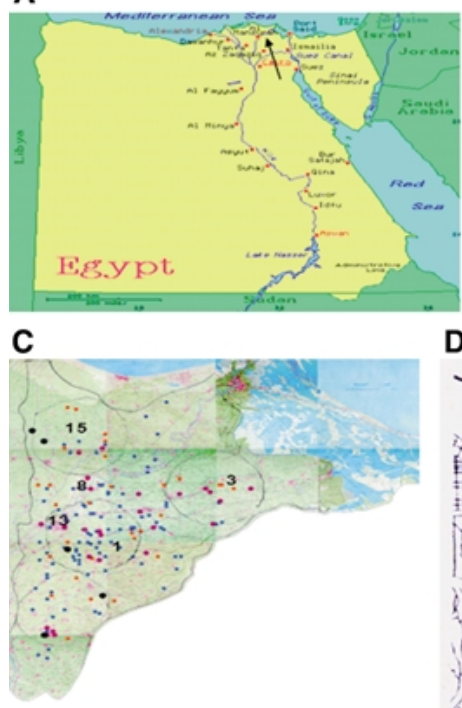

B

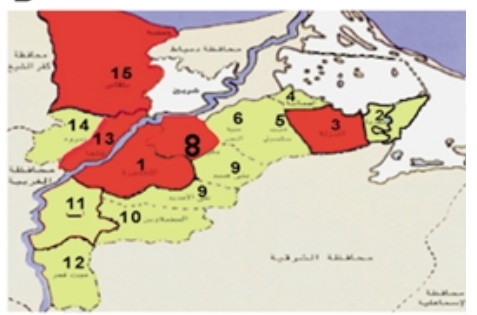

E

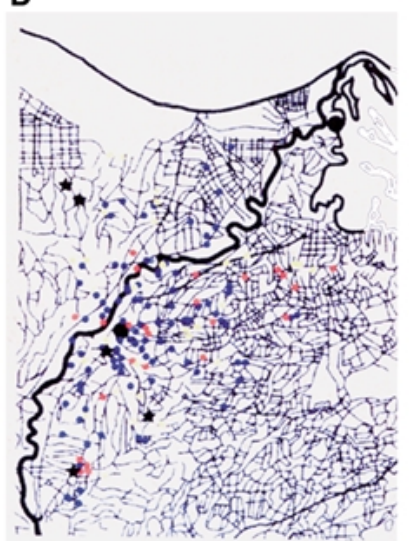

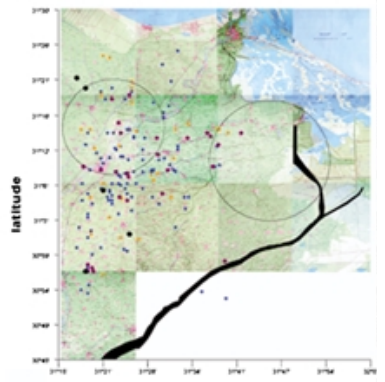

Fig. 1. Geographical distribution of pancreatic cancer cases in Dakahleia Province, Egypt. (A) Map of Egypt. (B) Map of Dakahleia Province showing districts of clustering in red and districts without clustering in yellow. (C) Map of Dakahleia Province on which the residences of patients with pancreatic cancer are plotted (dots). Blue $=1$ case, orange $=2$ cases, red $=3-10$ cases, and black $=$ more than 10 cases in the same spot (D) Map of the clustered pancreatic cancer cases on the map of water channels of the region. (E) Map of Dakahleia Province showing location of the suspected polluted water channel (Bahr El-Bakar) and its distribution in relation to the surrounding clustering of cases.

Table 1. Monte Carlo simulation of distribution of all patients with pancreatic cancer by district in Dakahleia Province, Egypt, 19952000

\begin{tabular}{llllr}
\hline & & $\begin{array}{l}\text { No. of } \\
\text { Datients observed }\end{array}$ & $\begin{array}{l}\text { No. of patients } \\
\text { expected }\end{array}$ & Rank $^{\mathrm{a}}$ \\
\hline 1 & 872,239 & 100 & $\mathbf{7 2}$ & $\mathbf{1}$ \\
2 & 140,068 & 12 & 12 & 384 \\
3 & 247,349 & 30 & $\mathbf{2 0}$ & $\mathbf{1 8}$ \\
4 & 82,179 & 7 & 7 & 38 \\
5 & 60,833 & 0 & 5 & 1000 \\
6 & 229,203 & 15 & 19 & 1000 \\
7 & 110,145 & 5 & 9 & 1000 \\
8 & 280,835 & 33 & $\mathbf{2 3}$ & $\mathbf{1 7}$ \\
9 & 140,254 & 1 & 12 & 1000 \\
10 & 420,854 & 27 & 35 & 1000 \\
11 & 395,272 & 17 & 33 & 1000 \\
12 & 612,203 & 21 & 50 & 1000 \\
13 & 289,947 & 37 & $\mathbf{2 4}$ & $\mathbf{2}$ \\
14 & 208,426 & 1 & 17 & 1000 \\
15 & 420,755 & 60 & $\mathbf{3 5}$ & $\mathbf{1}$ \\
\hline
\end{tabular}

Note: Figures in bold represent.

${ }^{a}$ Figures in bold represent statistically significant clustering of patients in these districts.

ulation in the 15 districts (CAPMAS 2001). The 1996 census data with its annual expected change in population size was the source of the population data (CAPMAS 2001).

Subjects 50 years or older constituted between $14 \%$ and $17 \%$ in various districts, with a median of $16 \%$. Among the
Table 2. Monte Carlo simulation of distribution of men with pancreatic cancer by district in Dakahleia Province, Egypt, 1995-2000

\begin{tabular}{lrrrr}
\hline District & Sample size & $\begin{array}{l}\text { No. of patients } \\
\text { observed }\end{array}$ & $\begin{array}{l}\text { No. of patients } \\
\text { expected }\end{array}$ & Rank $^{\mathrm{a}}$ \\
\hline 1 & 445,616 & 55 & 46 & 96 \\
2 & 72,982 & 5 & 7 & 1000 \\
3 & 128,325 & 22 & $\mathbf{1 3}$ & $\mathbf{1 5}$ \\
4 & 42,354 & 3 & 4 & 1000 \\
5 & 31,355 & 0 & 3 & 1000 \\
6 & 114,436 & 13 & 12 & 412 \\
7 & 50,787 & 3 & 5 & 1000 \\
8 & 142,640 & 21 & 15 & 76 \\
9 & 71,451 & 1 & 7 & 1000 \\
10 & 210,274 & 15 & 22 & 1000 \\
11 & 206,145 & 11 & 21 & 1000 \\
12 & 314,560 & 18 & 32 & 1000 \\
13 & 146,413 & 29 & $\mathbf{1 5}$ & $\mathbf{2}$ \\
14 & 104,831 & 1 & 11 & 1000 \\
15 & 210,649 & 39 & $\mathbf{2 1}$ & $\mathbf{1}$ \\
\hline
\end{tabular}

Note: Figures in bold represent.

${ }^{a}$ Figures in bold represent statistically significant clustering of patients in these districts.

five districts where we observed clusters, subjects 50 years or older constituted $14 \%$ in districts 1 and 3,15\% in district 8 , and $16 \%$ in districts 13 and 15 . Thus, the respective proportion of older subjects in districts with observed clusters were all around or below the median value of older subjects in the 
Table 3. Monte Carlo simulation of distribution of women with pancreatic cancer by district in Dakahleia Province, Egypt, 19952000

\begin{tabular}{|c|c|c|c|c|}
\hline District & Sample size & $\begin{array}{l}\text { No. of } \\
\text { patients observed }\end{array}$ & $\begin{array}{l}\text { No. of patients } \\
\text { expected }\end{array}$ & $\operatorname{Rank}^{\mathrm{a}}$ \\
\hline 1 & 426,623 & 45 & 25 & 1 \\
\hline 2 & 67,086 & 7 & 4 & 116 \\
\hline 3 & 119,024 & 8 & 7 & 395 \\
\hline 4 & 39,825 & 4 & 3 & 301 \\
\hline 5 & 29,478 & 0 & 2 & 1000 \\
\hline 6 & 114,767 & 2 & 7 & 1000 \\
\hline 7 & 59,358 & 2 & 4 & 1000 \\
\hline 8 & 138,195 & 12 & 8 & 106 \\
\hline 9 & 68,803 & 0 & 4 & 1000 \\
\hline 10 & 210,580 & 12 & 13 & 1000 \\
\hline 11 & 189,227 & 6 & 11 & 1000 \\
\hline 12 & 297,643 & 3 & 17 & 1000 \\
\hline 13 & 143,534 & 8 & 9 & 1000 \\
\hline 14 & 103,595 & 0 & 6 & 1000 \\
\hline 15 & 210,106 & 21 & 13 & 14 \\
\hline
\end{tabular}

Note: Figures in bold represent.

${ }^{a}$ Figures in bold represent statistically significant clustering of patients in these districts.

province. Therefore, the clusters we found were not dominated by the "older population" effect in the five districts. We also carried out a statistical analysis to assess whether there was any difference in the distribution of age groups across districts. We used the age groups of $<50,50-59,60-69$, and $>70$ years, and the results showed that the age group distribution was very similar across districts. Therefore, our current cluster analysis did not take into account the effect due to age.

One of the five districts was located in the Manzala lagoon region (no. 3) in the northeast corner of Dakahleia Province, and the other four districts were located along the eastern (Damietta) branch of the Nile.

As we described in the statistical methods section, Monte Carlo method generated an empirical distribution of pancreatic cancer cases under the null hypothesis assuming no clustering. $\lambda$ is the statistical value that measures the modality of clustering. Large-values for $\lambda$ indicate high clustering effect. For example, as illustrated in Table 1, under the assumption of no clustering, district 1 was expected to have only 72 cases compared to the true observed value of 100 . The rank was based on comparing the $\lambda$ calculated from the true observed data to the $999 \lambda$ s calculated from simulated data by assuming no clustering. The rank of 1 for district 1 demonstrated that the $\lambda$ from our observed data was greater than all $999 \lambda$ 's from simulated data, i.e., top 1 among $1000 \lambda$ 's. This can also be interpreted as having significant clustering effect at 0.001 level.

\section{Discussion}

In the hypothesis-generating study described here, we identified geographical clusters of patients with pancreatic cancer in restricted sectors of the northeast Nile delta region and highlighted a possible association between this clustering and environmental pollution. The clustering, which occurred in 5 of 15 districts studied (nos. 1, 3, 8, 11, 13, and 15), was unusual and was not related to district population size.
Some have argued that a spatial analysis such as ours may detect variations in disease incidence, because exposure to environmental carcinogens is unlikely to be evenly distributed geographically (Järup et al. 2002). Indeed, there appear to be regional differences in pancreatic cancer risk, as determined by our Monte Carlo simulation rankings, and significant heterogeneity in environmental exposures across the districts of the province. Such geographic heterogeneity in environmental exposure, in turn, suggests that pollution may have contributed to the clustering we observed.

As already mentioned, cigarette smoking is the only known risk factor for pancreatic cancer (Potter 2002). However, as recently observed, smoking usage does not differ between areas of disease clustering and areas of nonclustering (Soliman et al. 2001). Thus, smoking does not appear to adequately explain why and where the disease clusters formed.

Our study revealed significant clustering of patients with pancreatic cancer in the Manzala district (district 3). Several previous studies have shown the Manzala region to be the most polluted region in Egypt (Siegel et al. 1994, 1995; Stanley et al. 1996; Stanley and Warne 1998; El Raey et al. 1999; Dekov et al. 2001; Dewidar and Khedr 2001; Reinhardt et al. 2001; Shamrukh et al. 2001). The Manzala Lagoon located within the region is the largest brackish body of water $(\sim 1071$ $\mathrm{km}^{2}$ ) on the Mediterranean coast of Egypt. The lagoon, which is about $50 \mathrm{~km}$ long and at most $39 \mathrm{~km}$ wide, is shallow $(<2 \mathrm{~m})$ and has an average depth of approximately $1 \mathrm{~m}$. The Ginka Subbasin in the southeast sector of the lagoon (Figure 1E) called the "black spot" because of its high levels of contamination (Saad 1990)-receives from the drains "open sewers such as Bahr el Bakar" not only discharges that are rich in heavy metals, but also municipal sewage, industrial effluent, and agricultural runoff (El Raey et al. 1999). Important to note is the fact that the Manzala lagoon supplies about $50 \%$ of the total Egyptian fish catch, and that more than $90 \%$ of the residents of the northeast Nile delta eat fish from this lagoon (Bishay and Yuossef 1977).

A number of studies have examined environmental pollution in Egypt. The Nile delta Core and Sample Database for the Mediterranean Basin Program (MEDIBA) study, which ran from 1985 to 1994 and was sponsored by the Smithsonian Institution, assessed the effect of the Aswan High Dam on the soil and water on northern Egypt. The MEDIBA study, in conjunction with other soil investigations, showed that the construction of the Aswan High Dam in Egypt has led to dramatic changes in the Nile River's chemistry (Siegel et al. 1994, 1995; Stanley 1996; Stanley and Warne 1998; El Raey et al. 1999; Dekov et al. 2001; Dewidar and Khedr 2001; Reinhardt et al. 2001) a massive increase in the use of chemical fertilizers by Egyptian farmers (Shamrukh et al. 2001) and a related increase in the heavy metal and pesticide content of the soil (El-sokkary 1992; Siegel et al. 1994; AbdelHaleem et al. 2001). A comparison of mean heavy metal concentrations in soil sample sediments from 1968 (baseline) and 1993 (more recently) taken during the MEDIBA study showed a consistent increase in heavy metal concentration and exceptionally high levels of heavy metals in soil sediment cores in the Manzala lagoon and neighboring regions in Dakahleia Province. For example, the cadmium levels in the soil of Dakahleia Province rose from $0.2 \mathrm{ppm}$ in 1968 to $0.5 \mathrm{ppm}$ in 1993 (Siegel and Abdel Basset 2002). 
Previous studies have illustrated the high pollution levels in water of regions of areas of clustering shown in this study. For example, Wahaab and Badawy (2004) showed that Manzala Lake, where cluster 3 is located, had documented heavy metal pollution and that shallow underground water largely surpassed the World Health Organization standards for drinking water. Other studies from the same region showed that 136 from the Nile water in this region revealed exceptionally high levels of heavy metals and organochlorine pesticides, which is a source of cadmium (Osfor et al. 1998a; Abbassy et al. 2003). Extensive dumping of agricultural and industrial chemical byproducts into the water of areas of clustering should have significant impact on water pollution in these regions (AbdelSabour and Abdel-Bassel 2002).

Interestingly, cadmium levels are high not only in the soil of the Manzala region but also in the sera of fishermen and other apparently healthy residents there (Osfor et al. 1998b). Moreover, these high serum levels are even much higher than serum levels of populations in other parts of Egypt. For instance, children and adolescents from highly polluted areas of Cairo have serum cadmium levels higher than those of U.S. children (Samir et al. 1997; Hossny et al. 2001). Moreover, residents of Dakahleia Province and fishermen of the Manzala Lagoon have serum levels 15 and 30 times higher, respectively, than those of the Cairo residents (Samir et al. 1997; Osfor et al. 1998b; Hossny et al. 2001).

Exposure to cadmium has been linked to known risk factors for pancreatic cancer (Schwartz and Reis 2000). For example, cadmium accumulates in the body with increasing age, and age is known to be a risk factor for pancreatic cancer (Pinot et al. 2000). Smoking leads to increased cadmium exposure because cadmium is a known contaminant of cigarettes (Bernard and Lauwerys 1984). One study found that the pancreas of a smoker contains twice as much cadmium as the pancreas of a nonsmoker (Elinder et al. 1976).

The other four districts that contained significant clusters of patients with pancreatic cancer (districts 1, 8, 13, and 15) lie near the distal end of the Damietta branch of the Nile around Mansoura City. Because of the increasing pollution of the Nile and continued discharge of agricultural and industrial wastes along its course (El-sokkary 1992; Siegel et al. 1994; AbdelHaleem et al. 2001), we postulate that the pollution of common water sources in this region may be a main factor in the pancreatic clustering in these 4 districts. Figure 1D shows the clustering of pancreatic cancer cases on the map of small water channels of the region. Although the clustering of cases may show a concordance with the water channels for districts 1,8 , and 13, that concordance is lacking for district 15 . Other reasons for clustering in districts $1,8,13$, and 15 could be the occurrence of the Faraskour Dam on the Damietta branch of the Nile at the distal end of cluster 1 . The dam was built in this region because of the slow water current in the area of the four districts. The slow water flow in this region is also proved by the existence of a large pumping station in the cluster area. Residents of district 1 exhibit exceptionally high levels of heavy metals (Mortada et al. 2002). District 13 contains a fertilizer plant that is apparently responsible for the relatively high nitrate content in agricultural products grown in the district (el-Ayoty and Abdelhamid 1989). A recent study (Zohny 2002) has classified District 15 as a highly polluted soil with cobalt due to the intense industrial pollution activity in the
Dakahleia region. Industries in the region include chemical, petrochemical, electric appliances, textile, leather, plastic, furniture, and fertilizer industries (El-Sherif 2002). In addition to these well-documented industrial activities, there are a number of small-scale industries that may not be rigorously following strict waste disposal regulations.

The clustering of pancreatic cancers in our general study population and in men, but not in women, is surprising. One possible explanation for this is that Egyptian men are frequently exposed to both residential and occupational water pollution, whereas Egyptian women are exposed mainly to residential water pollution.

We have no reason to think that the pancreatic cancer clustering observed in this region was due to a hereditary or familial disposition to pancreatic cancer, even though an inherited genetic defect is suspected to be the major risk factor in $10-15 \%$ of all pancreatic cancers. Consanguinity is prevalent in Egypt, reaching up to $30 \%$ in the Nile delta region (Temtamy et al. 1994), but there is no evidence to indicate that consanguinity is any more or less prevalent in one district than in another. Furthermore, the population of the Nile delta region is ethnically homogeneous (Krings et al. 1999).

In general, our study has a number of positive aspects. 1) The large numbers of patients we identified with pancreatic cancer enabled us to analyze their geographical distribution by district. 2) Medical care was available free of charge to all residents in our study area (Sallam 1998), which suggests that patients would not have been prevented economically from seeking diagnosis and follow-up care. Also, there are no cultural or social barriers for medical care of pancreatic cancer in Egypt that would limit medical care for women. 3) Transportation did not appear to be a barrier to seeking medical care, because patients came to the GSC in Mansoura from all the most distant parts of the province (e.g., district 3). 4) Our access to the records of other cancer centers besides the GSC in Mansoura helped us to identify those few patients from the region whose disease was diagnosed at the GSC but not treated there. This eliminated selection bias and strengthened our populationbased study. 5) Access to confirmed pathological diagnoses of tumors and our ability to obtain survival information allowed us, in the absence of a histopathological diagnosis, to confirm the diagnosis of pancreatic cancer (Soliman et al. 2002). 6) Access to maps of the region giving detailed information relative to location of water channels, agriculture, and industries allowed us to link clustering of patients with pollution sites. 7) We were able to buttress our findings with the plethora of published research on the extent and types of environmental pollution in the study region. 8) The relatively low degree of migration to and out of the region gave us confidence that our residence data were reasonably accurate at the time of this analysis (Aly and Shields 1996).

However, our study also has limitations. First, information on occupational exposures was lacking, because occupational data are not routinely collected from patients during the admission process at Egyptian hospitals. Had such information been available, it would have added a critical dimension to our study. Second, for purposes of this study, we assumed that familial aggregation of pancreatic cancer did not play a major role in our observed clustering. The clustering did not appear to be linked to any hereditary/familial predisposition to pancreatic cancer because of the different family names of cases. 
Instead, it appeared to be linked to environmental pollution because the five districts of clustering lie in the most polluted region in Egypt. Third, a plausible explanation of the lower number of districts with significantly high rate in women as compared to men is statistical power.

We conducted a recent case-control study to investigate the association between serum cadmium levels and pancreatic cancer in Dakahleia Province. Our results showed significantly higher serum cadmium levels in pancreatic cancer patients than control subjects (Kriegel et al. in press). In future studies, we will try to further clarify the causes of pancreatic cancer clustering by examining more closely the environmental and occupational exposures, dietary intake, and family history of cancer in each district and conducting more spatial analyses of the five clusters we have identified.

Acknowledgments. We thank Dr. Ibrahim Seifeldin at Tanta Cancer Center and Dr. Somaia Ezzat at Damietta Cancer Center in Egypt for their help in retrieving patient data. This work was supported in part by a grant from Eli Lilly Research, a grant from the Topfer Fund for Cancer Research at M. D. Anderson Cancer Center, and grants CA K07 090241 and CA 99513 from the National Cancer Institute and by the National Institutes of Health through the University of Michigan's Cancer Center Support Grant (5 P30 CA46592).

\section{References}

Abbassy MS, Ibrahim HZ, Abdel-Kader HM (2003) Persistent organochlorine pollutants in the aquatic ecosystem of Lake Manzala, Egypt. Bull Environ Contam Toxicol 70:1158-1164

Abdel-Haleem AS, Sroor A, El-Bahi SM, Zohny E (2001) Heavy metals and rare earth elements in phosphate fertilizer components using instrumental neutron activation analysis. Appl Rad Isot 55:569-573

Abdel-Sabour MF, Abdel-Basset N (2002) The effect of industrial activities on zinc alluvial Egyptian soil determined using neutron activation analysis. J Env Sci (China) 14:330-332

Alavanja MC, Blair A, Masters MN (1990) Cancer mortality in the U. S. flour industry. J Natl Cancer Inst 16:840-848

Aly HY, Shields MP (1996) A model of temporary migration: the Egyptian case. Int Migration 34:431-447

Badawy MI, Wahaab RA, Abou Waly HF (1995) Petroleum and chlorinated hydrocarbons in water from Lake Manzala and associated canals. Bull Environ Contam Toxicol 55:258-263

Bernard A, Lauwerys R (1984) Cadmium in human population. Experentia 40:143-151

Bishay HM, Yuossef SF (1977) Some aspects of the hydrography and physico-chemical characteristics of fisheries of lake Manzala. United Arab Republic Bulletin of the Institute of Oceanography and Fishery 1977

Cantor KP, Silberman W (1999) Mortality among aerial pesticide applicators and flight instructors: follow-up from 1965-1988. Am J Ind Med 36:239-247

CAPMAS (2001) Central Agency for Public Mobilization and Statistics. Statistical year book Cairo, Egypt

Dekov VM, Komy Z, Araujo F, Van Put A, Van Grieken R (2001) Chemical composition of sediments, suspended matter, river water and ground water of the Nile (Aswan-Sohag traverse). Sci Total Environ 201:195-210

Dewidar K, Khedr A (2001) Water quality assessment with simultaneous landsat-5TM at Manzala lagoon, Egypt. Hydrobiologia 457:49-58
El Raey M, Firhy O, Nasr S, Dewidar K (1999) Vulnerability assessment of sea level rise over Port Said governorate, Egypt. Env Mon Ass 56:113-128

el-Ayoty SA, Abdelhamid AM (1989) Animal and Poultry Production Department, Faculty of Agriculture, Mansoura University, Egypt. Effect of the presence of a urea fertilizer plant on the nitrate content of berseem and constituents of milk and blood of buffaloes. Archiv fur Tierernahrung 39:491-498

Elinder C-G, Kjellström T, Friberg L (1976) Cadmium in kidney cortex, liver, and pancreas from Swedish autopsies. Arch Environ Health 31:292-302

El-Sherif H (2002) Description of Egypt with information. Information and Decision Support Center, Cairo, Egypt

El-sokkary IH (1992) Trace metals in sediments and waters: Case study from Egypt. In: Vernet JP, (ed) Impact of heavy metals on the environment. Elsevier Publications, Amsterdam, pp 355379

Falk RT, Pickle LW, Fontham ET, Correa P, Morse A, Chen V, Fraumeni JJ Jr (1990) Occupation and pancreatic cancer risk in Louisiana. Am J Ind Med 18:565-576

Forastiere F, Quercia A, Miceli M, Settimi L, Terezoni B, Rapiti E, Faustini A, Borgia P, Cavariani F, Perucci CA (1993) Cancer among farmers in central Italy. Scand J Work Environ Health 19:382-389

Fryzek JP, Garabrant DH, Harlow SD, Severson RK (1997) A casecontrol study of self-reported exposures to pesticides and pancreas cancer in Southeastern Michigan. Int J Cancer 72:62-67

Gusten H, Heinrich G, Weppner J, Abdel-Aal MM, Abdel-Hay FA, Ramadan AB (1994) Ozone formation in the greater Cairo area. Sci Total Environ 155:285-295

Hossny E, Mokhtar G, El-Awady M, Ali I, Morsy M, Dawood A (2001) Environmental exposure of the pediatric age groups in Cairo City and its suburbs to cadmium pollution. Sci Total Environ 273:135-146

Issa RM (1994) Water quality studies of the River Nile (from the High Dam Lake to Burulus). Egypt. J Anal Chem 3:48-54

Järup L, Best N, Toledano MB, Wakefield J, Elliott P (2002) Geographical epidemiology of prostate cancer in Great Britain. Int $\mathrm{J}$ Cancer 97:695-699

Ji BT, Silverman DT, Dosemeci M, Dai Q, Gao YT, Blair A (1999) Occupation and pancreatic cancer risk in Shanghai, China. Am J Ind Med 35:76-81

Ji BT, Silverman DT, Stewart PA, Blair A, Swanson GM, Baris D, Greenberg RS, Hayes RB, Brown LM, Lillemoe KD, Schoenberg JB, Pottern LM, Schwartz AG, Hoover RN (2001) Occupational exposure to pesticides and pancreatic cancer. Am J Indust Med 39:92-99

Kriegel AM, Soliman AS, Zhang Q, El-Ghawalby N, Ezzat F, Soultan A, Abdel-Wahab M, Fathy O, Ebidi G, Bassiouni N, Hamilton SR, Abbruzzese JL, Lacey MR, Blake DA (In press) Serum cadmium levels in pancreatic cancer patients from the East Nile delta region of Egypt. Environ Health Perspect

Krings M, Salem AE, Bauer K, Geisert H, Malek AK, Chaix L, Simon C, Welsby D, Di Rienzo A, Utermann G, Sajantila A, Paabo S, Stoneking M (1999) mtDNA analysis of Nile River Valley populations: a genetic corridor or a barrier to migration? Am J Hum Genet 64:1166-1176

Kulldorff M, Nagarwalla N (1995) Spatial disease clusters: Detection and inference. Stat Med 14:799-810

Lawson AB (2001) Tutorial in biostatistics: disease map reconstruction. Stat Med 20:2183-2204

Mack TM, Peters JM, Yu MC, Hanisch R, Wright WE, Henderson BE (1985) Pancreas cancer is unrelated to the workplace in Los Angeles. Am J Ind Med 7:253-266

Mallin K, Berkeley L, Young Q (1986) A proportional mortality ratio study of workers in a construction equipment and diesel engine manufacturing plant. Am J Ind Med 10:127-141 
Maruchi N, Brian D, Ludwig J, Elveback LR, Kurland LT (1979) Cancer of the pancreas in Olmstead County, Minnesota, 19351974. Mayo Clinic Proc 54:245-249

Mortada WI, Sobh MA, el-Defrawy MM, Farahat SE (2002) Reference intervals of cadmium, lead, and mercury in blood, urine, hair, and nails among residents in Mansoura city, Nile delta, Egypt. Environ Res 90:104-110

Norell S, Ahlbom A, Olin R, Erwald R, Jacobson G, Lindberg-Navier I, Wiechel KL (1986) Occupational factors and pancreatic cancer. Br J Ind Med 43:775-778

Osfor MM, Abd el Wahab AM, el Dessouki SA (1998a) Occurrence of pesticides in fish tissues, water and soil sediment from Manzala Lake and River Nile. Nahrung 42:39-41

Osfor MMH, El Dessouki SA, El-Sayed A, Higazy RA (1998b) Relationship between environmental pollution in Manzala Lake and health profile of fishermen. Nahrung 42:42-45

Park RM, Mirer FE (1996) A survey of mortality at two automobile engine manufacturing plants. Am J Ind Med 30:664-673

Partanen T, Kauppinen T, Degerth R, Moneta G, Mearelli I, Ojajarvi A, Hernberg S, Koskinen H, Pukkala E (1994) Pancreatic cancer in industrial branches and occupations in Finland. Am J Ind Med 25:851-866

Pinot F, Kreps SE, Bachelet M, Hainaut P, Bakonyi M, Polla BS (2000) Cadmium in the environment: Sources, mechanisms of biotoxicity, and biomarkers. Rev Environ Health 15:299-323

Porta M, Malats N, Jariod M, Grimalt JO, Rifa J, Carrato A, Guarner L, Salas A, Santiago-Silva M, Corominas JM, Andreu M, Real FX (1999) Serum concentrations of organochlorine compounds and K-ras mutations in exocrine pancreatic cancer. Lancet 354:21252129

Potter JD (2002) Pancreas cancer-We know about smoking, but do we know anything else? Am J Epidemiol 155:793-795

Raymond L, Bouchardy C Les (1990) Facteurs de risque du cancer du pancréas d'après les études épidémiologiques analytiques. Bull Cancer 77:47-68

Reinhardt EG, Stanley DJ, Schwarcz HP (2001) Human-induced desalinization of Manzala lagoon, Nile delta, Egypt: Evidence from isotopic analysis of benthic invertebrates. J Coastal Res $17: 431-442$

Rotimi C, Austin H, Delzell E, Day C, Macaluso M, Honda Y (1993) Retrospective follow-up study of foundry and engine plant workers. Am J Ind Med 24:485-498

Saad AHM (1990) State of the Egyptian delta lakes, with particular reference to pollution problems. Regional Symposium of Environmental Studies (UNARC), Alexandria, Egypt, May 12-14

Sallam I (1998) Health care in Egypt [Letter]. Lancet 352:1632

Samir M, Magdy S, El Fetoh AA (1997) Air pollution in relation to allergic and nonallergic rhinitis. Arch Otolaryngol Head Neck Surg 123:746-748
Schwartz GG, Reis IM (2000) Is cadmium a cause of human pancreatic cancer? Cancer Epidemiol Biomarkers Prev 9:139-145

Shamrukh M, Corapcioglu MY, Hassona FAA (2001) Modeling the effect of chemical fertilizers on ground water quality in the Nile Valley aquifer, Egypt. Ground Water 39:59-67

Sheffet A, Thind I, Miller AM, Louria DB (1982) Cancer mortality in a pigment plant utilizing lead and zinc chromates. Arch Environ Health $37: 44-52$

Siegel FR, Slaboda ML, Stanley DJ (1994) Metal pollution loading, Manzala Lagoon, Nile delta, Egypt: Implications for aquaculture. Environmental Geology 23:89-98

Siegel FR, Gupta N, Shergill B, Stanley DJ, Gerber C (1995) Geochemistry of Holocene sediments from the Nile Delta. J Coastal Res 11:415-431

Silverstein M, Park M, Marmor M, Maizlish N, Mirer F (1988) Mortality among bearing plant workers exposed to metalworking fluids and abrasives. J Occup Med 30:706-714

Slebos RJ, Hoppin JA, Tolbert PE, Holly EA, Brock JW, Zhang RH, Bracci PM, Foley J, Stockton P, McGregor LM, Flake GP, Taylor JA (2000) K-ras and p53 in pancreatic cancer: Association with medical history, histopathology, and environmental exposures in a population-based study. Cancer Epidemiol Biomarkers Prev 9:1223-1232

Soliman AS, Levin B, El-Badawy SA, Nasser S, Raouf AA, Khaled $\mathrm{H}$, El-Hattab OH, Chamberlain RM (2001) Planning cancer prevention strategies based on epidemiologic characteristics: An Egyptian example. Public Health Rev 9:1-11

Soliman AS, El-Ghawalby N, Ezzat F, Bondy ML, Soultan A, AbdelWahab M, Fathy O, Ebidi G, Bassiouni N, El-Ghawalby A, Levin B, Abbruzzese JL (2002) Unusually high rate of young-onset pancreatic cancer in the East Nile Delta region of Egypt. Int J Gastrointest Cancer 32:143-151

Sparks PJ, Wegman DH (1980) Cause of death among jewelry workers. J Occup Med 22:733-736

Stanley DJ, McRea JE Jr, Waldron JC (1996) Nile Delta Drill Core and Sample Database for 1985-1994: Mediterranean Basin (MEDIBA) Program. Smithsonian Institution report no. 37, Smithsonian Institution, Washington, DC

Stanley DJ, Warne AG (1998) Nile Delta in its destruction phase. J Coastal Res 14:794-825

Temtamy SA, Kandil MR, Demerdash AM, Hassan WA, Meguid NA, Afifi HH (1994) An epidemiological/genetic study of mental subnormality in Assiut Governorate, Egypt. Clin Genet 46:347-351

Wahaab RA, Badawy MI (2004) Water quality assessment of the River Nile system: An overview. Biomed Environ Sci 17:87-100

Walter SD (1993) Visual and statistical assessment of spatial clustering in mapped data. Stat Med 12:1275-1291

Zohny EA (2002) Cobalt in alluvial Egyptian soils as affected by industrial activities. J Environ Sci (China) 14:34-38 